\title{
A Call for Educational Models Based in Interdisciplinarity, Diversity, Change
}

\author{
NICHOLAS C. MARKOVICH \\ Louisiana State University \\ (now at North Arizona University)
}

USA

In order to be effective and meaningful for students, educational venues ought reflect the creative and technological essence of the culture they serve, indeed, show leadership in these areas. They must also be forward thinking, anticipating the future state of being within a culture. Education must, in a sense, predict the status and expectations of future culture and find strategies viable for the students future existence. Education above all teaches about "being" and strategies for "being" within varying realms of reality. Being is in crisis and architectural education reflects that crisis today as it did at the turn of this century, when paradigmatic shifts occurred from Beaux Arts based teaching methodologies to Modernist/Bauhaus methods to present Post Modern methodologies. Today's shift is one that moves from earlier Twentieth Century industrialized based paradigms to one that is now based in information and interpretation. This shift is critically rooted in change and the resultant ability to cope within an ongoing cloud of increasingly complex systems of understanding. The most important single change needed in the education of architects and designers is the implementation of education models based in diversity and change within interdisiplinary frameworks.

Dominated by conservative policies for much of the later half of this century, climaxing in the ultra right wing policies of the past twelve years, much of architectural education now reflects the value systems of Republicanism. Educational leadership and process sits stagnating in a political milieu based in conservative, non-progressive posture, causing at the very least, conflict and often confusion as to future directions and educational strategies. Conservative politics in education is evidenced by an increasing intrusion of the profession and outside governing boards into educational activities. What often seems appropriate to professional groups only complicates and often hinders progress and development in educational realms.

The old conservative guard, with some exceptions, promotes educational standardization, acting through architecture's professional organizations. As we approach the twenty-first century, the gap between the demand for a viable intellectual base for the student of architecture, approaching the twenty first century and the standards of the old guard is increasingly more disparate. Old approaches toward increased homogeneity, standardization and objectivity, in realms of absolutes, should come to closure. Processes of individuality, creativity, flexibility and interpretation become doomed to conservative control systems, forcing education as training rather than education as intellectual development. Thus, there is conflict between those who motivate from past restrictiveness and those who must work within frameworks of creativity in diversity and multifaceted responsibility. As we approach the third millennium, we owe our students more than what we have proven so far. We owe them a vision of the future and strategies for success and productivity in the constancy of change.

Conservatism, as we have seen predominate the politics of the past twelve years, calls for maintaining the status quo, ignoring social and cultural issues in progressive terms, turning back the clock on such issues as environmental protection, civil rights, personal rights, the Bill Of Rights, health care and human dignity for all. In 1992, the American public voiced its disgust of such policies, in 1994, there was a verification of such. We are confused. In 1992 seventy percent of the popular vote was cast in opposition to conservative policies which have left us in a present economic and moral disarray. This seventy per cent of the electorate voting for change was comprised of a new majority, a coalition of the previously disenfranchised. Their call was for an end to the arrogance of conservative power and its tendency toward exclusion, elitism, linear hierarchies of power, divisionism and disenfranchisement of non-white, non-male, non-straight, non-protestant members. The new call was for an end to policies which are choking the very soul of this nation. Many of us watched with horror at the tactics which have been employed over the past twelve years, where a politically correct conservative posture placed those who believed otherwise into an unpatriotic, reactionary, fringe group. We dangerously approached Fascism. We gagged as the Buchanan's, the Falwell's, the Quayle's and the Bush's attempted to divide us, encapsulate us in their narrow vision of a correct existence. Their dominance over the recent past has particularly hurt public education and set an agenda against growth, change and diversity. It appeared the same 
conservative attitudes predominated the professional hierarchy of artifacts and affiliated organizations, also negatively impacting architectural education, particularly Schools in the public realm and forcing a mindset of stagnation and conservatism. Indeed, one may say this was a search for mediocrity, where one does not honor excellence but sameness.

Right wing conservatism shows clearly in architectural education and professional organizations have in many ways forced schools to codify and standardize their educational intent and methodologies. Not only has the education of architects been impacted, so too has the making of young architects by national professional boards and committees. The evidence of increased intellectual/educational strangulation is clear. Accreditation criterion have been more clearly and objectively defined. Licensing testing has become increasingly more difficult and selective, tending toward a specific ideology of practice, all at some point influence education in conservative ways. Such practices are geared more towards exclusion rather than inclusion or intelligence. Those policies promote a process that reeks havoc with the concept of learned vs. creative intelligence, promoting a value system based in definitive rights and wrongs, objectivism, militaristic hierarchies and advancement procedures; a system based often more in who knows who than how good one is. At a recent architects committee meeting in New Orleans a student panel member said that her most important resolution was to tell students that self promotion should be on first priority. The President of the AIA called for an end to the studio experience. She and he received great applause from the mostly professional crowd. This was to me evidence of the low standard our ethical base has dropped. I strive for a model based more on interaction, sharing of goals and administration, diversity of experience.

New initiatives of continuing education by professional organizations are further evidence of control over the status of architectural intellectualism. Conservative policies tend towards less diversity allowing greater control by a power elite, greater surety of so-called politically correct values and the denigration of creative thought in lieu of a surer, more codified method of thinking. The education 2000 initiative appears a move to gain more control over the education of architects, pre and post licensing, implementing a highly conservative and potentially stifling control over the whole process of "becoming" in architecture from the freshman year in College. These conservative policies should be left in the past and a new model of more inclusive, diverse substance set in motion. Education accrediting boards should be dominated by educators. Licensing practices and testing should be totally reevaluated within new contexts and under a balanced political aegis. Continuing education should solely be the province of accredited Schools, not professional organizations. Indeed, it may be illegal for the AIA to offer accredited education as long as the NAAB and its accreditation of University programs exists.
Present world culture calls for new models of existence and action. It is no wonder in this decade that President Clinton won on a platform of "change." Change is scientific fact. If we study history well, we know that change is an important factor in the psyche of world cultures as we approach a new century, particularly as we approach a new millennium. The clock cannot be turned back. The dynamics of change in every facet of existence are affecting the earth in an ever tightening spiral of concern. From administrator to student, we must accommodate change.

Concepts now are perceived within realms of understanding, truths are shared amongst other truths, absolutes change in cycles of evolution. It is important then to understand genres, clouds of relative information, in a Jungian sense. Invention and interpretation are necessary in the context of an information, intelligence based culture, world. The old world was more linear, more Christian, more absolute, more physical than mental, more industrial. It has usurped itself and new models have emerged, showing that the momentum of change exists with or without us. Acceptance to new models based in cyclical processes of understanding, rather than linear ones, diversity rather than exclusion, and shared information and administration of ideas, rather than secrecy, is essential. Present educational processes that promulgate clear objective answers, military models of learning, are already outmoded. They no longer satisfy the student of this era, who is based on information and vision.

Architectural education would best be served by a more phenomenological model of education. This is a problem best left to educators and theorists. Educators are involved daily in the theory and practice of education which is dynamically different than the theory and practice of the office. As noted by the AIA brochure entitled "Future Beginnings: Directions in Officing," the office of the future will be distributed, decentralized in its organization power, omnidirectional in its communication, information intensive in its resource use, innovative in its culture, and its primary use will be in the exercising of creativity. Old office directions were described as hierarchical, centralized, rigid, one way, formal, closed, repetitive, senior management, uniform, linear. Reward in the new model is based on performance; in the old model, seniority or individual connections. Unfortunately present political structures in education may not impact the mainstream of the profession for some years. Nonetheless, one must be educated to think in realms of understanding within which one can apply ethical and meaningful decision making the essence of which is interdisciplinary. We ought to think of education as nurturing life and intellect, rather than specifically "the profession." In this realm of change, students and the profession will be able to diversify and at the same time discover realms of understanding most applicable to their needs, as well as set new models for the next cycle of change accordingly.

Teaching is a skill and a profession in its own right and will increasingly need to be respected as such by architectural professionals. Not any architect can teach. Both 
Medicine and Law are presently looking at new models of education, where the processes of learning "genres" of intelligence are respected, leaving behind traditional methods based in specificity. The profession should concentrate on increased inclusion and face the increasing inducement of other professions into ours with the realization that conservativism has in many ways left our profession negligently behind. This is no more clearly evident than in the economic situation our profession finds itself. No longer, and this has been true for over thirty years, should a competent, intelligent student of this profession find themselves, after having earned a masters degree with a minimum wage. Let's accept change into more diverse systems and head in economic expansion. This may mean radical change in our professional institutions. So be it. Education can lead the way to this new vision.

A future model of an architectural faculty should include, an equal percentage of practitioner-teachers, research-teachers, and teacher-teachers, those who concentrate on new methodologies and approaches to teaching. In this light, the Architecture School would be involved in an ongoing self evaluation which is primarily initiated from within and pointedly aware of those necessities of change without. In response, accrediting boards which should be dominated by educators will work within new genres of understanding, respecting diversity in programs and educational innovation. Allow education to help lead the way beyond present dilemmas in which all of us find ourselves. Let's add new diversity and meaning to the term "architect". Each entity, professional and educational must respect the autonomy and the importance of each other. Where education is meant to lead is in it's own realm; i.e., research, methods of learning, modes of learning, subject matter and intellectual development. It is meant to be exploratory on all levels, searching for new answer and new context of "being". Like the profession, it must respond to new contexts and cultural challenges. It cannot be dictated to from without and cannot be impinged upon by professional organizations to alter its mission. There sometimes appears to be a fear on the part of practitioners that educators aren't preparing one for the profession. It is primarily our job to teach our students to think. You must support us and trust us. The educational community is searching for the best answers within a limited set of resources. Do not hinder our goals in a quagmire of conservative policy making. Look for ways to help elevate the dignity of the educator as professional.

The administration of architecture programs also fits in a model of change. All participants in an architectural school community should be included in the ongoing process of change and growth. Ultimate decision making can no longer remain in the hands of one or two individuals. It is unproductive and fractionalizing, also a waste of important brain power; showing a lack of respect for the commonality of coworkers and creating we-they situations. If one is in education, one must be an active, full time participant willing to accept the necessity of keeping curricula current with and ahead of its time. This is an immense job, an ongoing dilemma which will never be resolved. Old methods of the dominant Dean, Director should come to an end. It is a great travesty that those who want to maintain this type of conservative hierarchy in the 90's are the greatest adversaries to the immediate needs of educators and education; the result is poor leadership in education, followed by a dysfunctional milieu. In this era those policies are bound to produce friction and levels of resentment amongst competent colleagues who no longer expect disenfranchisement. Students would be well advised to avoid such schools, as the conservatism ultimately chokes the educational process and poorly initiates one to the realities of the future.

An alternative administrative process is one where all educators in a given situation use their intelligence for the good of the whole by being allowed to participate in all decision making which affects the group. Likewise, all members of a faculty should be held accountable for the well being of the school. Students should be actively involved in the administration of the school and maintain seats on all policy making boards with voting authority. This interaction will help prepare by example for the office of the future.

I have heard many an old traditionalist ridicule the work of Wolf Prix. Essentially they are making fun of that which they do not want to understand. Unfortunately this exemplifies to a current dilemma based in conservative non-acceptance of change. New modes of experimental thinking are beyond understanding within realms of understanding from the past. Current students have a great task in that they must remain open to change within their life span, never reaching absolutes. What seems right today, may be wrong tomorrow. As present processes of design teaching should tutor them, there are many right answers to choose from, some of which are better than others. In a changing realm of ideas, images and diagrams, the question of appropriate selection, ethical decision making, clear perception and empathy with human and environmental conditions become more important than rational Cartesian analysis, resulting in linear correctness. In a sense, the Jungian cloud has come into play, that body of knowledge from which we will continually derive new formats based on the knowledge of understanding derived within and from the collective whole. Abstraction becomes the essence of classroom procedure, i.e., one draws from or abstracts knowledge from this body, tests, verifies and establishes appropriate models of truth within given realms. In this light, education is both a collective experience and an individual experience. We are already fortunate to have the studio model in architecture, where this sort of experimentation and decision making takes place. This model should be extended to other modes of architectural education. The studio is a place of discovery of truth; a diverse, highly personal, yet communal and holistic truth.

While it is up to the Schools to lead in educational policy, it is clear that professional boards have stepped in to conservatively hold education at bay. I am not anti-profession, I am pro-education. Conservatives will likely label this kind of 
talk unpatriotic, solely for presenting a point of view which has not been fostered by the power elite. If I am labeled so, I feel in good company; danger comes when truth is so absolute it cannot be challenged. My hope is that education wakes to its duty and professional organizations look at diversity and reorganization of priorities in interdisciplinary ways. Old ways may function, but no longer work. Out of the acceptance of diversity and change can come strength. 